\title{
Identidade e ethos conservador na política cultural. Estudo comparado França-Brasil
}

\section{Identidad y ethos conservador en la política cultural. Estudio comparado Francia-Brasil}

\section{Identity and conservative ethos in cultural politics. Study comparing France-Brazil}

\author{
Marina Ramos Neves de Castro'
}

\author{
Palavras chave: \\ Política cultural \\ Identidade \\ Conservadorismo \\ Modernidade
}

Resumo:

O artigo discute o ethos identitário das políticas culturais conservadoras, observando as práticas de controle e disciplina da identidade pelo Estado. A reflexão é realizada com base numa perspectiva comparada, observando a conformação histórica das políticas culturais da França e do Brasil. Embora o interesse maior seja o caso brasileiro, a França constitui um elemento de comparação instigante, em função de seu pioneirismo no desenvolvimento de políticas culturais e da influência desse modelo sobre o Brasil e outros países. O artigo encontra duas dimensões estruturantes desse ethos, uma tendência à centralização e outra, à institucionalização. Essas duas tendências visam, historicamente, ao mesmo objetivo: o processo de promoção e de consolidação do Estado, elementocatalizador da política, na dinâmica de consolidação do Estado moderno. 
Resumen:

El artículo discute el ethos identitario de las políticas culturales conservadoras, observando las prácticas de control y disciplina de la identidad por el Estado. La reflexión se realiza sobre la base de una perspectiva comparada, observando la conformación histórica de las políticas culturales de Francia y Brasil. Aunque el interés mayor es el caso brasileño, Francia constituye un elemento de comparación instigante, en función de su pionerismo en el desarrollo de políticas culturales y de la influencia de ese modelo sobre Brasil y otros países. El artículo encuentra dos dimensiones estructurantes de ese ethos, una tendencia a la centralización y, otra, a la institucionalización. Estas dos tendencias apuntan históricamente al mismo objetivo: el proceso de promoción y de consolidación del Estado, elemento catalizador de la política, en la dinámica de consolidación del Estado moderno.

Palabras clave:

Política cultural

La identidad

Conservadurismo

Modernidad

\section{Keywords:}

Cultural heritage

Porto Maravilha

Territorialy

Social appopriation

Cultural policies

\section{Abstract:}

The article discusses the identitary ethos of conservative cultural policies, observing the practices of control and discipline of identity managed by the State. The reflection is carried out based on a comparative perspective, observing the historical conformation of the cultural policies of France and Brazil. Although the greater interest is the Brazilian case, France is a compelling element of comparison, due to its pioneering in the development of cultural policies and the influence of this model on Brazil and other countries. The article finds two structuring dimensions of this ethos, a tendency of centralization, and another, of institutionalization. These two tendencies historically aims at the same objective: the process of promoting and consolidating the State, a central dynamic for politics, in the consolidation of the modern State. 


\section{Identidade e ethos conservador na política cultural. Estudo comparado França-Brasil}

\section{Introdução}

O objetivo deste artigo é refletir a respeito de um dos elementos constitutivos do ethos - e da razão de ser - das políticas culturais: a questão identitária. Para além de uma perspectiva associada à democratização do acesso e dos direitos à cultura, que constitui a tônica dominante da produção científica mais contemporânea sobre as políticas culturais, desejamos explorar o elemento que, a nosso ver, conforma a motivação maior das políticas culturais conservadoras - e das políticas culturais em geral, em seu fundamento, por via da sua conformação histórica: as práticas de controle e disciplina da identidade pelo Estado.

Realizaremos nossa reflexão com base numa perspectiva comparada: observar a conformação histórica das políticas culturais de dois países, França e Brasil, destacando como, nelas, esse tema do controle e da disciplina da identidade se faz presente, geralmente de maneira indireta. Evidentemente nosso interesse maior é pelo caso brasileiro, espaço onde atuamos, como pesquisadora. Escolhemos a França como elemento de comparação porque, como observam Fumaroli (1992), Autissier (1999), Poirrier (2000), Regourd (2002) e Djian (1996), se trata do Estado pioneiro no desenvolvimento institucional de políticas públicas para o campo cultural, assim acumulando importante experiência que, efetivamente, se conforma como um modelo, no plano histórico, tanto para o Brasil como para diversos outros Estados.

Comecemos com um desenvolvimento desse modelo crítico - a suposição sobre o controle e a disciplina da identi- dade como ethos das políticas culturais. Comecemos com uma suposição, com uma suposição fundadora, a de que a política cultural, qualquer que seja, direta ou indiretamente, sugere um mito de origem, realizando um discurso propositivo sobre uma identidade conveniente ao Estado que a elabora e produz.

Ainda que sugira o contrário, ou que não o afirme objetivamente, a política cultural vincula-se a esse Estado, fundamentalmente, para representá-lo, ilustrá-lo e significá-lo. Assim, necessariamente coerente com a própria definição do Estado, pode-se dizer que a política cultural, nas suas origens conservadoras e exclusivistas, procura impor-se como porta-estandarte de uma identidade, criando os instrumentos estratégicos para que essa identidade se manifeste.

Para discutir essa hipótese, organizamos o artigo em quatro partes. Após esta breve Introdução, discutimos, no tópico 2, o modelo francês e, no tópico 3 , o modelo brasileiro. Buscamos perceber como o modelo brasileiro se deixa derivar do modelo francês, identificando algumas variáveis desse processo. Afinal, no tópico 4, procedemos à discussão de nossa hipótese.

\section{A invenção da política cultural: o "modelo francês"}

Buscamos fazer aqui uma síntese da política cultural elaborada na França, em sua perspectiva histórica, com o intuito de observar a constante interferência no setor e o processo de construção hegemônico das camadas intelectuais da sociedade francesa em sua associação com - Estado e de, a partir dessa observação, melhor compreender o caso em análise.

Partimos da observação de Djian (1996), que "la politique culturelle est une invention française", fruto de uma preocu- 
pação constante, dos poderes monárquicos ou republicanos, de se encarregar, em nome de uma mística nacional, da proteção de determinado patrimônio artístico e, por extensão, de encorajar a produção que, no futuro, conformará, ela também, esse patrimônio (DJIAN, 1996, p. 18).

A interferência direta do Estado na vida cultural francesa remonta ao início do século XVI com Francisco I. O rei, responsável pela criação do Collège des lecteurs au Royaume - que mais tarde se tornará o Collège de France -, diminuiu o poder e a tutela do clero sobre a população e o reino, promovendo uma deslatinização da comunidade intelectual. Após isto, ele tornou obrigatório a utilização da língua francesa nas redações de textos oficiais, anteriormente escritos em latim. Em seguida, por meio da criação dos Arquivos Nacionais, Francisco I

consacre l'effort de la royauté dans sa volonté inébranlable d'asseoir institutionnellement la nation France. II est d'ailleurs fort intéressant de signaler que les Archives dépendent, aujourd'hui comme hier, du ministère de la Culture et qu'elles en constituent historiquement le socle fondateur (DJIAN,1996, p. 95)."

No século XVII, numa ação de política cultural semelhante, o cardeal Richelieu criou a Academia Francesa, atribuindo-lhe a função de promover, legitimar, institucionalizar e regulamentaro uso da língua francesa através de uma política subjetiva nas relações que Estado mantém com a classe intelectual e artística. Pode-se ressaltar, nesse sentido, o exemplo de Le Discours de La Méthode, de René Descartes, publicado em 1637, que, por suainfluência, impôs a língua francesa como língua filosófica, levando-a a se apresentar como tal para o resto do mundo. Ainda no século XVII, Louis XIV procurou sustentar e encorajarum grande número de produções artísticas, com o objetivo de, por meio delas, ampliar a eficácia simbólica de seu poder. No seu reinado foi instituída a Comédie Française, e também foi criada a Surintendance des Bâtiments, Arts et Manufactures, permitindo a confluência da técnica com a ciência, como um elemento político de Estado.

No final do século XVIII, a percepção de importância da preservação do patrimônio histórico e cultural já estava presente no espírito público e uma perspectiva de "defesa" e "promoção" das artes, ou ao menos de algumas delas, era constantemente tematizada no Conselho de Estado. Isso fez com que o Estado criasse a Commissions de Monuments que passou a se encarregar de elaborar estratégias para a implantação de museus em todo o território francês, além de reunir e proteger as obras de artes. Em seguida, uma sequência de instituições relacionadas à política cultural, foi criada pelo Estado.Dentre as mais importantes, apontamos o Institut de France, o Conservatoire des Arts et Métiers e o Conservatoire National de Musique. Entretanto, é com a revolução que o Estado francês torna-se mais incisivo em estabelecer uma verdadeira política para gerir e administrar os bens culturais. Segundo Djian (1996, p. $65)$, é naquele momento que começam a nascer as políticas culturais na França.

No início do século XIX, com o primeiro Império, o Estado tornou-se paulatinamente mais presente, seja através da regulamentação das instituições já existentes - como através do decreto de Moscou, assinado em 1812, que definiu o papel da Comédie Française, seja através da criação de novas instituições diretamente vinculadas à cultura - como a Inspection Général des Monuments Historiques, seja através da política de restauração e conservação de monumentos históricos e artísticos.

O Segundo Império procurou ter o mesmo empenho e engajamento do Pri- 
meiro Império, dando continuidade à interferência do Estado no campo cultural, ou mesmo social, no território francês. Como reflexo da mudança ocorrida no plano cultural na França, cinco exposições foram organizadas no final do século XVIII; exposições estas onde sempre o Estado estava presente.

A III República, de maneira geral, não se interessou muito pelos assuntos culturais como ocorreu no período imediatamente anterior. No entanto, o novo governo interferiu, sobretudo, na vida mental da sociedade, ou seja, na superestrutura social, à medida em que se voltou em direção à educação. Não deixou de fazer o mecenato em relação aos artistas, mas o reduziude maneira significativa, priorizando sempre os membros das academias. Graças à proposição de priorizar a educação e a formação laica e republicana, a III República ganhou certa fama de "réputation d'incult" (DJIAN, 1996, p. 65).

A partir de 1936, com a chegada da esquerda à frente do Estado, uma política alternativa foi proposta para o cenário nacional. Os responsáveis por essas novas ações culturais foram o ministro da Instruction Publique et des Beaux-Arts e o ministro des Sports et aux Loisirs. Essa junção deu um caráter particular a essa nova política, que procurou promover o lazer e a cultura conjuntamente. Todavia, em relação a essa nova política social, o discurso democrático sempre permeou as ações desse Estado em direção às políticas aplicadas à cultura, tal como demonstra Huissman, citado por Monnier (1996, p. 66):

En réalisant une politique de loisir, en marquant sa volonté que toutes les classes de travailleurs soient amenées par étapes successives à une exacte compréhension de la culture, notre démocratie entend rompre avec dês erreurs qui onttrop duré."I
Uma idéia também presente em Djian:

Des centres d'éducation artistique sont crée setles auberges de jeunes sesontin vitées à se rapprocher dês activités de restauration dês monuments historiques. Dans le même temps, les musées sont ouverts les oirafin de faciliter l'accès aux travailleurs. Le régime de Vichy n'a d'autre ambitions que de restaurer un nouve lordre moral et culturel (DJIAN, 1996, p. 66). IV

A IV República, por sua vez, foi marcada por uma participação decisiva do Estado no ambiente cultural. Um dos fatores mais significativos desse período foi a participação das instituições de caráter não cultural no campo da cultura, assim como a participação de profissionais que acreditavam que a cultura e as artes constituíam "un enjeu essentiel pour la démocratie" (DJIAN, 1996, p. 67). Como exemplo, tem-se a criação do Centre National de Cinématographie sob a tutela do Ministère Du Commerce et de l'Industrie e a atuação de Jean Vilar em Avignon, no Thêatre National Populaire.

De Francisco I à IV República, pode-se observar que o discurso estruturador das políticas públicas do campo cultural - seja ele direcionado às Belas Artes, às Letras, à Ciência ou à Educação -esteve assentado sobre a crença na "grandeur de la France". Essa crença, que se instalou no discurso do Estado Francês durante aproximadamente cinco séculos, permeou todas as políticas públicas voltadas para o campo da cultura e marcou o período em questão.

A partir de 8 janeiro de 1959, com a V República, nasceu na França o Ministère des Affaires Culturelles. Ainda que o fato em si não signifique uma grande e ambiciosa política cultural, a participação de André Malraux, personagem proeminente da vida cultural e política nacional, enquanto Mi- 
nistre des Affaires Culturelles, resultou em significativa legitimidade à política cultural praticada pelo Estado. O incômodo era a parca receita destinada a este ministério, que deixava muito a desejar, e a grande resistência da maioria em relação a uma esquerda intelectual e artística mobilizada. Outro fator que caracterizou a gestão de Malraux foram os efeitos contraditórios de sua política, entre elitista, na qual o privilégio de constituição e preservação do patrimônio estava mais presente em detrimento da formação de público, e seu discurso democrático. Não obstante esse pode ter sido um dos fatores que levou a

Nourrir la fonction même de la culture dans la conscience collective des plus éclairés des citoyens et à, d'une certain efaçon, legitime le discours culturel produit par la puissance publique, autantil a, probablement par excès de zele intellectuel, affranchiles autres départements ministériels (éducation radio-télévision...) d'une responsabilité essentielle en la matière. (DJIAN 1996, p. 80). ${ }^{\vee}$

Serge Grazini (2000) compreende que "aussi embriqué soit-elle, la notion de politique culturelle apparaît tout au long de La VEME République comme une préocupation constante des différents gouvernements qui se sont succédé" (GRAZINI, 2000, p. 1). ${ }^{\mathrm{VI}}$

Para ele a política cultural constitui, na $V$ República Francesa, um verdadeiro motor catalisador da vida política. Isso porque "à travers la politique culturelle, il s'agit de faire en sorte que l'Etat soit au coeur du mouvement naturel de la société, qu'il organise et qu'il lui donne son sens" (GRAZINI, 2000, p. 3). ${ }^{\text {vII }}$

Ou seja, a política cultural catalisa a própria comunicação política do Estado: deve haver uma política de Estado para a cultura porque o Estado francês é o portador de uma mensagem universal, como testemunha sua história nacional.
Trata-se da famosa « exceção cultural », elemento nuclear de toda política cultural da V República e, portanto, da comunicação política do Estado.

Após os acontecimentos de 1968, durante a década de 1970, a maneira de se desenvolverem as políticas culturais mudou completamente. A partir deste período, a política cultural passou a se basear em uma filosofia mais aberta, mais democrática. Os movimentos sociais e, sobretudo estudantis, ocorridos no fim dos anos 60 e início dos anos 70, incitaram a uma liberdade criativa, privilegiando mais "le faire culturel" que o dirigismo aplicado anteriormente. Durante este tempo, foi produzido e difundido um discurso sobre a ação cultural. O orçamento do Estado para a área aumentou e um fundo público foi criado e destinado às ações inovadoras e experimentais, o que contribuiu para determinar o papel do Ministère des Affaires Culturelles no cenário administrativo e político do país. Esses anos foram de grande agitação, tanto no cenário social como no cenário político da cultura, a tal ponto que, entre 1969 a 1978, passaram pelo Ministère des Affaires Culturelles nada menos que sete diferentes ministros de Estado.

Os anos 1980 foram marcados pelo espírito dos "grands travaux" que caracterizaram o governo socialista de François Mitterand. Esse momento cultural foi encarnado e marcado por Jack Lang, seuministro da cultura. De certa maneira, as ações estabelecidas e desenvolvidas pelo governo foram legitimadas por uma grande parte da população, em especial por intelectuais, e isso se deu, diferentemente do momento anterior, sem grandes conflitos, provavelmente por três razões. A primeira foi de ordem ideológica,resultado de uma expectativa de mudança e de uma mobilização geral da sociedade francesa em torno do primeiro momento do governo Mitterand. A segunda foi de ordem política, vinculada à sua disputa com a ordem anterior, que 
se propõe a radicalizar as ações culturais para favorizar a "culture pour tous" e assim, criar um antagonismo de projetos, processo esse descrito por Moulinier (1995). E finalmente, o que definitivamente marcou o período, foi uma espécie de santificação da cultura, o lugar que a cultura ganhou no seio da nação, legitimada por um impulso social amplo que parecia resgatar a condição gloriosa da França do tabuleiro das relações internacionais, bem como também resgatou a autoestima do país.

Diversas ações de caráter múltiplo foram empreendidas por Jack Lang, e mudaram completamente o cenário cultural ou a vida cultural do país. Dentre as ações de caráter simbólico, podemos apontar o "prix unique du livre", que permitiu distinguir o "produto cultural", no caso o livro enquanto tal; a legitimação de acontecimentos sociais marginalizados, como o rock,o jazz criando assim "La Fête de la Musique"; a banda desenhada, o circo, a alta gastronomia (DJIAN, 1996, p. 87). Sua política tocou também a questão do direito autoral e a promoção e a institucionalização de iniciativas culturais regionais através do desenvolvimento de centros culturais científicos e técnicos em todo o território nacional.

Outro fato determinante para marcar a passagem de Jack Lang no Ministère des Affaires Culturelles é sua cumplicidade com o presidente da república francesa. Como aponta Dijan (1996, p. 83): "A la différence des sés prédécesseurs, Jack Lang sait mobiliser toute son énergie et as complicité avec François Mitterand pour défendre son budget". vIII Entretanto, não se pode deixar de considerar que "Il $y$ a, chez Lang, une propension à mobiliser toutes les énergie disponibles pour faire s'épanouir les 'gisements de la création' avec le souci légitime d'enmontrer les résultats (DJIAN, 1996, p. 90). ${ }^{\mathrm{X}}$

Observamos ainda as predisposições do presidente Mitterand em relação à cultura. Segundo Emmanuel Roux (1993), Mitterand fez da cultura sua arma secreta com o objetivo de tornar-se imortal, seja através de políticas simbólicas, seja através das grandes obras que caracterizaram sua gestão enquanto presidente da república, dentre as quais podemos apontar a Pyrâmide du Louvre, o cubo de l'Arche de La Défense, a criação do Institutdu Monde Arabe, a criação da Cité de la Musique, a criação da nova Bibliothèque National, as colunas do Palais Royal, dentre tantos outros.

Se Malraux conseguiu criar e gerir uma política cultural que antes não existia de forma institucionalizada foi Jack Lang quem conseguiuconsolidar sua legitimidade, pois foi a partir de sua gestão que o status conquistado pelo Ministère des Affaires Culturelles cresceu e se consolidou na vida social, cultural e, principalmente, política da França de hoje.

Então, falar de Malraux sem falar do governo e do Estado francês que estava por trás dele é cometer um equívoco. Por outro lado, falar de Jack Lang sem falar de Mitterand é cometer o mesmo erro. Ou seja, não importa a época; quem sustenta, quem legitima uma política cultural é todo um setor, uma camada da sociedade que conseguiu validar, legitimar e institucionalizar um discurso, mas que, portanto, só pode assim o fazer porque estava de posse do Estado, enquanto governo.

De Lang para os dias atuais houve uma tendência de manutenção e consolidação dessa construção histórica. A importância do Ministério da Cultura, bem como dasdemais instituições promotoras de políticas culturais e das políticas culturais como ação do Estado se tornam evidentes e presentes na tônica das propostas políticas, um ponto passivo, sobre o qual não pesam, normalmente, projetos de transformação mais radical. O que entra em questão, na diversidade dos projetos políticos para a cultura, é, basicamente, o orçamento a 
ser destinado ao setor. Sua importância e a forma de sua manutenção não constituem, efetivamente, um debate maior em todo o campo do espectro político do país.

\section{As políticas culturais no Brasil}

Durante um longo período da história brasileira, que parte dos tempos coloniais e alcança o período imperial, observa-se, senão a existência políticas culturais propriamente ditas, a produção de políticas de caráter social-religioso, que buscaram reprimir e hierarquizar posições, subordinando agentes sociais, definindo seus papéis de forma a impedir qualquer subversão à ordem constituída. O resultado desse processo foi a descontextualização da cultura africana e ameríndia em favor de uma europeização e de um embraquecimento cultural, o que significa a construção de uma ordem simbólica pautada pela hegemonia de referenciais europeus na construção simbólica da identidade e na institucionalização das práticas de poder.

As políticas públicas para o setor cultural, empreendidas pelo governo brasileiro até um momento recente denossa história, eram políticas comprometidas com a afirmação de uma determinada visão de mundo conservadora, própria das elites sudestinas e nordestinas e que tinham, por estratégia fundamental de sua reprodução social, a negação de todo conflito e de toda violência - simbólica, cultural, econômica e social - presente na formação da sociedade brasileira. Essas políticas foram influenciadas por intelectuais que acreditavam em uma identidade étnico-cultural homogênea, como resultado das misturas de raças presentes no território do Brasil, um pensamento que se consolidou e se tornou dominante à partir da penetração, no mainstream do pensamento brasileiro, da teoria culturalista de Gilberto Freyre. Esse pensamento possibilitou a consolidação de uma determinada hegemonia política e de um projeto de poder centrado nos interesses mercantis e industriais dos setores mais conservadores da sociedade.

A ideia de uma identidade nacional brasileira corresponderiaà generalização amalgamadora das diferenças étnicas e à obliteração do fato de que esse processo de 'mestiçagem' foi, na verdade, um processo violento de destruição e submissão de diversas culturas àquela dos colonizadores.

Podemos localizar os primórdios do pensamento que, mais tarde, produziu a matriz da política cultural brasileira, nos intelectuais que, nas décadas de 1920 e 1930,construíram essa matriz amalgamadora que foi a tese da mestiçagem pacífica. Esses intelectuais, segundo Pécaut (1990), quase sempre filhos das oligarquias nacionais, acreditavam na existência de uma identidade latente "confirmadas pela maneira de ser, pelassolidariedades profundas e pelo folclore" (PÉCAUT, 1990, p. 14). Era urgente, para eles "organizar a nação... e traçar uma cultura capaz de assegurar sua unidade..." (PÉCAUT, 1990, p. 15), ou meIhor, sua identidade, capaz deassegurar determinados interessesnacionais, baseados em uma unificação imperativa. Identidade construída de maneira hierárquica e arbitrária, que até os dias atuais conformam a ordem social, e porque não, também a regional, da sociedade brasileira.

Para melhor alcançar a padronização desejada, foi necessárioafirmaruma nação, conformando-a através de elementos simbólicos que produzissem um efeito, digamos assim, narcótico e que pudessem ser sustentados por um Estado presente, atuante e, necessariamente, centralizador dos processos de produção da subjetividade. Esses elementos simbólicos pautaram-se pela positivação das subjetividades identitárias nacionalistas e essa estratégia de ativação de um Estado centralizador pautou-se pela construção de um referencial de política cultural 
- ainda que não se usasse esse nome conservador e rigorosamente castrador de toda diversidade.

Esse projeto intelectual de organizar a nação e de produzir efeitos de identidade consolidou um primeiro elemento institucional com a criação do Serviço do Patrimônio Histórico e Artístico Nacional - SPHAN, hoje IPHAN - em 1937. A anatomia desse órgão indica, na sua formação, um apreço muito grande pela dimensão arquitetônica da cultura nacional e uma índole conservadora e focada, num primeiro momento, sobre formas arquitetônicas do centro-sul do país. Essa índole se explicava, em primeiro lugar, pelo predomínio de arquitetos na instituição, em detrimento da participação de outros profissionais e intelectuais das demais áreas. Em segundo lugar, pela concentração, na hierarquia superior doórgão, de intelectuais mineiros e paulistas. $\mathrm{E}$, enfim, em terceiro lugar, pela hegemonia e estabilidade adquirida e preservada pela instituição, presente até a gestão de Renato Soeiro em 1979, o que possibilitou, ou pelo desinteresse dos governos desse período, ou pelo desinteresse da sociedade civil, de maneira geral, pelopatrimônio histórico e artístico nacional -, a produção de uma cultura institucional de longa duração, pautada pela percepção centralizadora e conservadora da cultura. De fato, o SPHAN tinha, em seu discurso fundador, um caráter preservacionista acentuado e, em geral, justificado pela necessidade de promover a reprodução hegemônica das elites intelectuais sudestinas.

Fazendo referência à política direcionada para a cultura através do IPHAN, Arruda Falcão coloca que "a questão da preservação do patrimônio cultural nesses 45 anos raramente se transformou numa 'arena' importante no jogo ideológico, político e econômico nacional" (FALCÃO, 1984, p. 37).

Juntamente com o IPHAN, participavam da estrutura de política cultural brasileira durante os anos 30 e 40, o Instituto
Nacional do Livro, criando no mesmo ano do IPHAN, em 1937, a Biblioteca Nacional, a Casa de Ruy Barbosa, o Museu Histórico Nacional, o Museu de Belas Artes, o Serviço Nacional do Teatro - SNT, o Serviço de Radiodifusão Educativa e o Instituto de Cinema Educativo (MICELI, 1984, p. 55). Notemos que todas essas instituições possuíam duas características comuns. A primeira é que todas se localizavam na cidade do Rio de Janeiro, então capital federal; e a segunda é que atuavam de forma desarticulada entre si, promovendo ações isoladas sem um direcionamento estratégico. Esse tipo de "não política" para a cultura esteve presente no cenário nacional até a década de 1970, quando o cenário político do país se alterou drasticamentea partir do endurecimento do regime militar instalado em 1964.

Os anos 1970 constituem um novo momento de institucionalização da política cultural, no Brasil,caracterizada por uma participação maior do Estado na criação de órgãos de fomento à cultura de caráter nacional, num processo que podemos bem acompanhar por meio da discussão de Cohn (1984). Isso ocorreu devido ao caráter ideológico do endurecimento político dos anos 1960/70, pois foi graças ao acirramento do projeto estratégico do regime militar, cujas marcas foram os paradigmas da integração do território nacional e da substituição dos bens de consumo importados pelos fabricados no país.

Segundo Sérgio Miceli, a década de 70 "foi um período de aquecimento dos motores, de início de decolagem" (MICELI, 1984, p. 55) para as políticas e institucionalização da cultura no Brasil. Em agosto de 1973 foi lançado o Programa de Ação Cultural - PAC que tinha por objetivo abrir crédito a algumas áreas da produção cultural e possibilitar um diálogo com os meios artísticos e intelectuais com o intuito de, através desses atores, legitimar o regime político. Ou seja, legitimar um regime político utilizando políticas públicas para a 
área da cultura que pudessem agir de maneira subliminar no imaginário social.

Durante essa década, na gestão do ministro de Educação e Cultura, Ney Braga, implementaram-se políticas importantes visando a 'construção institucional' do campo cultural: o Conselho Nacional de Direito Autoral (criado em 1973, mas operando a partir de 1975), o Conselho Nacional de Cinema - Concine (criado em março de 1976), o lançamento da Campanha do Folclore Brasileiro (em setembro de 1975), a reformulação da Empresa Brasileira de Filmes - EMBRAFILME (criada em setembro de 1969 e reformada em 1975), da Fundação Nacional de Arte - FUNARTE (em dezembro de 1975) e a expansão do já existente Serviço Nacional do Teatro.

Tão importante quanto a criação de órgãos e instituições, nessa gestão, foi a implementação da Política Nacional de Cultura, primeiro plano oficial do Estado brasileiro que se propunha a nortear a presença governamental na área da cultura.

Ou seja, foi somente na década de 1970 que o IPHAN começou a perder o seu monopólio sobre as decisões e ações políticas para a área da cultura, não somente porque as novas instituições e as já existentes passaram a ter metas e funções específicas, mas, sobretudo, porque o IPHAN passou a estar subordinado ao Ministério de Educação e Cultura.

Outro dado importante a observar, neste cenário, foi a criação do Centro Nacional de Referência Cultural - CNRC, criado pelo Ministério de Indústria e Comércio e apoiado por diversos outros órgãos e instituições federais.Este Centro, que era ideologicamente diverso do IPHAN, devido, provavelmente a composição eclética de seu quadro de técnicos que era composto por designers, físicos, antropólogos, sociólogos e outros. Posteriormente,sua junção ao IPHAN, retomava a proposta original de Mário de Andrade - quando criou o instituto 42 anos antes - procurando, assim, corrigir os erros do passado, centralmente, a redução do conceito de patrimônio cultural aos bens históricos significativos para as elites nacionalistas.

Ressaltamos que todo o aparato institucional criado para que o Estado passasse a "mediar", através de programas e política de incentivo, as atividades culturais no Brasil, foi criado e implementado no contexto ideológico e político de um nacionalismo valorizado.

Esse processo ganhou importância com o regime militar, que renovou a ideologia nacionalista procurando, por meio dela, legitimar-se. Um processo intensificado por meio da associação das políticas públicas com o setor privado das telecomunicações e da produção de conteúdo televisivo (Rede Globo de Televisão) e da indústria editorial (Editora Abril, Jornal Estado de São Paulo).

Nesse sentido cabe notar, ainda, um momento de ampliação do consumo cultural, efervescência estudada por Ortiz (1986) e que se traduziu na ampliação do consumo de livros, revistas, discos, aumento da bilheteria de teatros e cinemas e, também, da audiência televisiva.

Na análise de Miceli (1984) a política cultural brasileira do período militar (1964-1985) teve sua ação de fomento caracterizada por dois fatores: seu clientelismo e seu assistencialismo. A primeira dessas características diz respeito à maneira, geralmente passiva e autosubordinada, como as demandas dos artistas e produtores culturais eram dirigidas e processadas pelas agências de fomento e pelos órgãos gestores da política cultural.

A segunda característica, por sua vez, refere como essas agências e órgãos passaram a apoiar os gêneros e lingua- 
gens artísticas que tinham mais dificuldade de sobreviver no mercado estruturado pela indústria cultural - como o teatro, o circo, a dança, a ópera e a música de concerto, e ainda o folclore, de modo geral.

Miceli (1984) também observa como a noção de "identidade cultural" foi usada, nesse momento brasileiro: sempre de uma forma ideológica, politicamente instrumental, enquanto visão idealizada e, de maneira alguma, como um processo marcado por contradições internas - o que é, naturalmente, evidente em toda a dinâmica cultural. Assim, a "identidade cultural" tematizada pela política cultural do Estado brasileiro, durante o regime militar, estava pautada pelo compromisso com a padronização, e não com a responsabilidade de respeitar e promover a pluralidade cultural, processo evidente e enraizado na diversidade social, regional e étnica do país.

Um mapeamento do processo de organização institucional das políticas culturais brasileiras pode ser encontrado em Ortiz (1986), Rubim (2007) e Calabre (2009). Nesses autores é recorrente a crítica ao modelo conservador do mainstream das políticas culturais no país e a procura por soluções que viabilizem uma gestão democrática do setor.

Com o processo da redemocratização do país e durante todo o período de democracia que prossegue de 1985 ao golpe de Estado de 2016 o país experimentou duas forças divergentes no campo de suas políticas culturais: a tendência conservadora, arraigada à experiência histórica, e a tendência em prol da democratização do acesso à cultura e à liberdade do fazer cultural. Diversos autores, como Barbalho (2016); Rubim; Barbalho, Calabre (2015); Calabre (2015); Leitão; Guilherme (2014); Barbalho (2013); Gameiro; Carvalho (2013); Calabre (2009); Rubim (2007), dentre outros, vêm discutindo os processos contemporâneos da política cultural no Brasil e ressaltando os esforços das gestões Gilberto Gil e Juca Ferreira no Ministério da Cultura como um avanço importante e decisivo em direção a essa perspectiva democrática. Não sendo nosso propósito discutir esse processo neste trabalho, apenas o referimos, para que se leve em conta a sua magnitude e as possibilidades de ruptura que ele engendra. Com efeito, o que nos interessa é justamente o seu oposto: o ethos conservador e suas práticas de controle e disciplina da identidade.

Dessa maneira, pode-se estabelecer uma relação entre o modelo de políticas culturais dos anos 80 , e mesmos posteriores, com o padrão, a concepção e a forma da noção de cultura estabelecida pela indústria cultural. Não que as políticas culturais tenham se convertido em protótipos ou em plataformas propulsoras das indústrias culturais - embora em alguns casos isso tenha realmente acontecido mas pelo fato de que a visão de mundo redutora de conflitos, padronizadora dos costumes e simplificadora dos processos passou a demarcar a ação e a concepção teórica dos modelos de política cultural.

Nesse sentido, podemos falar num proto-padrão de política cultural. Um modelo que se conforma em meio ao choque sociocultural da entrada em operação dos grandes sistemas nacionais de produção da cultura massificada.

Os elementos centrais desse modelo são os seguintes: a concepção de cultura como uma unidade conceitual; a atribuição, à política cultural, da responsabilidade de gerenciar conteúdos; um instinto de difusão; uma mística de derivação de fontes, raízes e referências.

Pensamos que não apenas a política cultural do regime militar foi tributária desse modelo, mas que, também as políticas culturais do Estado brasileiro, poste- 
riores a esse momento, também o foram. Da mesma forma, acreditamos que o proto-padrão fundado pela indústria cultural atingiu muitas experiências estaduais e municipais brasileiras.

\section{Discussão}

Como acima sugerimos, nossa hipótese de partida foi a de que, ainda que sugira o contrário, ou que não o afirme objetivamente, a política cultural vincula-se a esse Estado, fundamentalmente, para representá-lo, ilustrá-lo e significá-lo.

Dessa maneira, necessariamente coerente com a própria razão de ser do Estado, pode-se dizer que a política cultural, nas suas origens conservadoras e exclusivistas, procura impor-se como porta-estandarte de uma identidade, criando os instrumentos estratégicos para que essa identidade se manifeste.

Esse processo parece estar presente nos dois casos que descrevemos, França e Brasil. De todo o processo histórico francês, que resumimos destacando alguns elementos, percebe-se dois vetores estruturantes: uma tendência à centralização, tanto institucional como geográfica e, outra, à institucionalização, por meio do processo de produção de instituições fortes, capazes, dessa maneira, a controlar o processo.

Essas duas tendências visam, historicamente, ao mesmo objetivo: o processo de promoção e de consolidação do Estado, elemento catalisador da política, na dinâmica de consolidação do Estado moderno. Pode-se perceber que, presentes no bojo das instituições e das políticas que referimos acima, essas tendências estiveram a serviço de um projeto geral: consolidar o Estado. E a cultura é um dos elementos centrais para a constituição desse projeto, pois a consolidação do Es- tado se associa à capacidade deste em se colocar como representante de uma dada coerência: a coerência identitária que desvelaria, pretensamente, o substrato de legitimação de todo Estado moderno.

É nesse sentido que compreendemos as políticas culturais como uma força conservadora, responsável pela consubstancialização do poder estatal. Seu fim seria a produção de coerências nacionais.

O caso brasileiro, percebido em suas disposições históricas, sugere uma reprodução do modelo francês. Não há uma variação expressiva nas duas tendências que caracterizam, historicamente, o modelo conservador das políticas culturais francesas, tanto a tendência à centralização como a tendência à institucionalização. Tal como na França, as políticas culturais do Estado brasileiro estiveram comprometidas, historicamente, com a prática conservadora geral do controle da identidade.

Essa prática se deu de forma diferenciada e variada. Na proto-política cultural do processo colonizador, por meio do genocídio dos povos indígenas e da negação das etnias e dos direitos básicos das populações indígenas, africanas e mesmo dos demais excluídos sociais da sociedade colonial. Já na história constituída das políticas públicas nomeadas como "culturais", por meio do cerceamento e restrição do financiamento, da ausência de diálogo, da inexistência de perspectivas de ação nos campos não convencionalizados daquilo que se entende por cultura.

Nos dois casos o controle da diversidade étnica, identitária, social e política parece estar nos fundamentos da ação do Estado no campo da cultura. A política cultura parece servir para disciplinar a identidade - e, assim, para controlar a diversidade e a heterogeneidade inerentes à vida social, e não para apoiar a sua dinâmica real. 
Trata-se, em nossa compreensão, do ethos conservador que fundamenta o Estado moderno e que tem, na domesticação da diversidade cultural, um de seus desafios estruturadores.

Esse ethos se constitui como a própria razão de ser do Estado moderno, hipótese que é colocada por Souza Santos:

sob a égide do capitalismo, a modernidade deixou que as múltiplas identidades e os respectivos contextos intersubjetivos que a habitavam fossem reduzidos à lealdade ao Estado, uma lealdade devoradora de todas as possíveis lealdades alternativas... A globalização das múltiplas identidades na identidade global tornou possível pensar uma identidade simétrica do Estado, global e idêntica com ele, a sociedade (SANTOS, 1994, p. 38).

Ou seja, para Souza Santos, a ruptura do sistema da communitas medieval, o triunfo da subjetividade individual sobre a coletiva, da subjetividade abstrata sobre a contextual, o advento da sociedade de mercado e normatização da propriedade individual - em síntese, dos fenômenos que caracterizam a própria Modernidade, em seus fundamentos - geraram a necessidade da criação do super-sujeito, o Estado Liberal.

Porém, esse Estado, que emana da sociedade, respaldando-se no contrato social da ordem moderna, teria dado início ao processo de alienação, exclusão e amalgamamento dos diversos agentes sociais nele presentes.

Essa força amalgamadora, por sua vez, baseada numa noção de "racionalidade descontextualizada e abstrata crescentemente colonizada pelo instrumentalismo e pelo cálculo científico" (SANTOS, 1994, p. 38), procurou engendrar uma identidade padronizadora das perspectivas culturais diversas que compunham a sociedade.
De acordo com Souza Santos, houve na Europa uma forte contestação a essa descontextualização cultural, com consequente polarização das identidades hegemônicas resultantes da dialética da Modernidade, que seriam o indivíduo e o Estado. Exemplos dessas forças contestadoras teriam sido o romantismo e o marxismo.

A contestação marxista se propunha a recontextualizar a identidade "através do enfoque das relações sociais de produção, no papel constitutivo destas, nas ideias e nas práticas dos indivíduos concretos e nas relações assimétricas e diferenciadas destes com o Estado" (SANTOS, 1994, p. 38), ou seja, contestação baseada no vínculo de classes.

A contestação romântica, por sua vez, proporia uma busca radical pela identidade, fenômeno que implicaria

uma nova relação com a natureza e a revalorização do irracional, do inconsciente, do mítico e do popular e o reencontro com o outro da modernidade, o homem natural, primitivo, espontâneo, dotado de formas próprias de organização social (SANTOS, 1994, p. 38).

$E$, ainda, que essa busca pela identidade glorificaria "a subjetividade individual pelo que há nela de original, irregular, imprevisível, excessivo, em suma, pelo que há nela de fuga à relação estatal-legal" (SANTOS, 1994, p. 38).

Para o autor, a contestação romântica propõe a recontextualização das identidades pela afirmação de três vínculos principais: o religioso, o étnico e o natural. Através deles, supunha-se, as identidades poderiam confrontar-se ao Estado moderno e mesmo superá-lo.

Essa constatação romântica se evidencia em diversas formas que variam segundo os valores culturais de uma socie- 
dade. Como exemplo dos mais evidentes, ou, diria, dos mais eloquentes, colocamos o romantismo alemão nas artes plásticas, na pintura, no teatro, na música e a sua valorização da natureza ou do ambiente natural e cultural, que está acima do indivíduo e ao qual o indivíduo submete-se. É significativa a relação entre as ideias de espaço e de identidade, tal como observa Debuyst (1998) para a conformação da cultura política conservadora.

No entanto, nenhuma dessas formas de contestação, sejam os "vínculos" românticos, seja a crítica marxista,conseguiram, nos últimos cem anos, afirmar uma identidade alternativa que fosse de encontro aos interesses desse Estado moderno. Aliás, bem ao contrário, o Estado moderno soube apropriar-se do fundo referencial dessas contestações e utilizá-las em benefício da própria estratégia de afirmação da identidade nacional que propunha. Veja-se como ocorreu esse processo em cada um dos "três vínculos" propostos, citando-os por meio de exemplos:

- A marginalização do "vínculo" religioso está presente em todo o processo histórico do ocidente. Alguns exemplos deste processo de descontextualização (e tentativas de uma contextualização pró Estado) estão presentes na expulsão dos judeus e mouros da península lbérica; na Santa Inquisição; no confisco de bens da Igreja, seja na Europa ou na América e, principalmente, na rivalidade entre Igreja e Estado sobre o controle da educação dos cidadãos (SANTOS, 1994, p. 37).

- Quanto ao "vínculo" étnico, este, em benefício de alguns Estados, foi absorvido pelo conceito de nação:

...um conceito inventado ora para legitimar a dominação de uma etnia sobre as demais, ora criar um denominador sociocultural comum suficientemente homogêneo para poder funcionar como base social adequada à obrigação política geral e universal exigida pelo Estado, autodesignado assim como Estado-Nação (SANTOS, 1994, p. 37).

Para Souza Santos o conceito de nação varia de acordo com a bases étnicas do Estado. Esse autor utiliza o Brasil como exemplo de Estado-Naçãono qual a identidade cultural foi, e é, sempre, sinônimo de identidade nacional, no qual o elemento étnico, caracterizador do discurso do Estado-Nação brasileiro, seria a mistura harmônica de diversas etnias.

O vínculo natural, descontextualizado frente à expansão do capitalismo comercial europeu, teria se legitimado pela ação de conquista do novo mundo. Assim, verificou-se a descontextualização da subjetividade do homem natural, ou seja, do índio da América diante do homem europeu: "a subjetividade do outro(o ameríndio) é negada pelo 'fato' de não corresponder a nenhuma das subjetividades hegemônicas da modernidade em construção: o indivíduo e o Estado" (SANTOS, 1994 , p. 38), justificando-se igualmente a exploração da natureza pelo homem e a exploração do homem pelo homem.

Colocando a questão no plano brasileiro, observamos um embate tradicional entre a proposição de uma identidade nacional, afirmada pelo GovernoFederal num movimento de colonialismo interno, e as diversas identidades regionais, afirmadas, historicamente, como formas de repulsão a essecolonialismo.

Também o Estado brasileiro, na sua afirmação de uma identidade nacional comum a todos os brasileiros, usou das estratégias usadas pelos demais estados nacionais. E também as regiões brasileiras procuraram contestar essa ideia, oua da evocação romântica dos "vínculos" de origem. 
O discurso, seja textual seja imagético, utilizado por ambos, possui uma evocação romântica no que se refere aos "vínculos" de origem.

Nesse embate, pode-se observar que a "identidade" não seria, propriamente, o fruto de uma razão histórica, ou de uma razão natural, mas fruto da necessidade política de uma elite - que é representada pelo Estado ou que o é pelas diversas forças institucionais presentes nas regiões. A "identidade" de que se fala, portanto, em ambos os casos, estaria mais próxima de um projeto de identificação do que de um processo de identidade, propriamente dito.

É por essas razões que o controle e a disciplina da identidade se tornam o mote estruturante das políticas culturais. Os exemplos aqui discutidos, França e Brasil, ilustram a existência e a continuidade desse modelo. Nos dois casos tem-se o vetor dominante de um ethos conservador no campo das políticas culturais. As experiências de democratização e de tolerância, ou mesmo valorização dos efeitos sociais decorrentes da diversidade social contrabalanceiam, mas também demonstram a prevalência histórica desse modelo.

\section{Bibliografia}

AUTISSIER, Anne-Marie. L'Éurope culturelle en pratique. Paris: Ministère des Affaires Étrangères, 1999.

BARBAlho, Alexandre. Política cultural e o desentendimento. Fortaleza: IBDCult, 2016.

BARBALHO, Alexandre. Política cultural. In: GOVERNO DA BAHIA. Coleção Política e gestão culturais. Salvador, 2013.
CALABRE, Lia. Notas sobre os rumos das políticas culturais no Brasil nos anos 2011- 2014. In: RUBIM, Antonio Albino Canelas; BARBALHO, Alexandre; CALABRE, Lia(org.). Políticas Culturais no Governo Dilma. Salvador: EDUFBA, 2015.

CALABRE, Lia. Políticas Culturais no Brasil: dos anos 1930 ao século XXI. Rio de Janeiro: FGV, 2009.

COHN, Gabriel. A Concepção Oficial da Política Cultural nos Anos 70. In: MICELI, Sérgio (org.). Estado e Cultura do Brasil. São Paulo: Difel, 1984.

DEBUYST, Frédéric. Espaces et identités: Propositions interpretatives. In: DEBUYST, Frédéric ;YEPEZ. Ivan (orgs.). Amérique Latine: espaces de pouvoir et identités collectives. Louvain La Neuve: Bruylant, 1998.

DJIAN, Jean-Michel. La Politique Culturelle. Paris: Le Monde, 1996.

FALCÃO, Joaquim Arruda. Política Cultural e Democracia: A preservação do patrimônio histórico e artístico nacional. In:MICELI, Sérgio (org.). Estado e Cultura no Brasil. São Paulo: Difel, 1984.

FUMAROLI, Marc. L'Etat culturel. Essai sur une religion moderne. Paris: Falois, 1992.

GAMEIRO, Rodrigo; CARVALHO, Cristina Amélia. Reposicionando as lutas sociais na emergência das polítias públicas na cultura - o exemplo do movimento mangue. In: CARVALHO, Cristina Amélia; DOURADO, Débora Paschoal; GAMEIRO, Rodrigo (org.). Cultura e transformação políticas e experiênciasculturais. Porto Alegre: Dacasa Editora, 2013.

GRAZINI, Serge. La communication culturelle de l'État. Paris: PUF, 2000.

LEITÃO, Cláudia Sousa; GUILHERME, Luciana Lima. Cultura em movimento: memórias e reflexões sobre políticas públicas e práticas de gestão. Fortaleza: Armazém da Cultura, 2014.

MICELI, Sérgio. O Processo de "Construção Institucional" na Área Cultural Federal - Anos 70. In: MICELI, Sérgio (org.). Estado e cultura no Brasil. São Paulo: Difel, 1984.

MONNIER, Gérard. Des beaux-Arts aux arts plastiques. Le Manufacture, 199. In: DJIAN, Jean-Michel. La Politique culturelle. Paris: Le Monde, 1996. 
MOULINIER, Pierre. Politique culturelle et décentralisation. Paris: CNFPT, 1995.

ORTIZ, Renato. Cultura brasileira e identidade nacional. São Paulo: Brasiliense, 1986.

ORTIZ, Renato. Românticos e Folcloristas. Rio de Janeiro: Olho d’Água, 1992.

PÉCAUT, Daniel. Os intelectuais e a política no Brasil: Entre o povo e a nação. São Paulo: Ática, 1990.

POIRRIER, Philippe. L'État et la culture en France au XXe siècle. Paris: Le Livre de Poche, 2000.

REGOURD, Serge. L'exception culturelle. Paris: PUF, 2002.

ROUX, Emmanuel. Vaste querele pour grande bibliothèque. Le Monde (jornal), 07 de janeiro de 1990 , p. 30.

RUBIM, Antonio Albino Canelas. Políticas culturais no Brasil: tristes tradições e enormes desafios. Salvador: EDUFBA, 2007.

RUBIM, Antonio; BARBALHO, Alexandre; CALABRE, Lia. (orgs.). Políticas Culturais no Governo Dilma. Salvador: EDUFBA, 2015.

SANTOS, Boaventura de Sousa. Modernidade, Identidade e a Cultura de Fronteira. Tempo Social, Revista de Sociologia, São Paulo-SP, USP, 5 (1-2), 1993 - editado em1994.p. 31-53.

SFEZ, Lucien. La politique simbolique. Paris: PUF, 1993.
I Marina Ramos Neves de Castro. Doutoranda em Antropologia pela Universidade Federal do Pará. Contato: mrndecastro@gmail.com

!! "Consagra o esforço da realeza em sua vontade irremovível de instituir a nação francesa. Aliás, é muito interessante assinalar que os Arquivos dependem, hoje tal como no passado, do Ministério da Cultura e que eles constituem, historicamente, o seu núcleo fundador". Tradução da autora.

III "Realizando uma política voltada para o lazer, marcando sua vontade de que todas as classes trabalhadoras sejam levadas, por etapas sucessivas, a uma exata compreensão da cultura, nossa democracia acredita que rompe com os erros que já tanto duraram". Tradução da autora.

IV "Centros de educação artística estão sendo criados e os albergues da juventude estão sendo convidados a se aproximar das atividades de restauração dos monumentos históricos. Ao mesmo tempo, os museus passaram a ser abertos em horários noturnos, afim de permitir o acesso dos trabalhadores. O regime de Vichy não tem outras ambições senão as de restaurar uma nova ordem moral e cultural". Tradução da autora.

V "Alimentar a função da cultura na consciência coletivados cidadãos mais esclarecidos legitima, de uma certa maneira, o discurso cultural produzido pelo poder público, ainda que, provavelmente por excesso de zelo intelectual, tenha liberado os outros departamentos ministeriais (educação, rádio, televisão...) de sua responsabilidade essencial na matéria". Tradução da autora.

VI "Por mais ambígua que seja, a noção de política cultural aparece em toda a Quinta República como uma constante preocupação de sucessivos governos que se sucedem". Tradução da autora.

VII "Através da política cultural, trata-se de fazer que o Estado esteja no centro do movimento natural da sociedade que ele próprio organiza e que lhe dá sentido". Tradução da autora.

VIII "À diferença de seus predecessores, Jack Lang soube mobilizar toda a sua energia e cumplicidade com François Mitterand para defender seu orçamento". Tradução da autora.

IX "Há em Lang uma propensão a mobilizar todas as energias disponíveis para promover essas explosões de criatividade, mas com a preocupação, legítima de mostrar os resultados". Tradução da autora.
Recebido em 12/02/2018

Aprovado em 26/02/2018 